\title{
Transformation of serum-susceptible Escherichia coli 0111 with p16S/ux plasmid to allow for real-time monitoring of complement-based inactivation of bacterial growth in bovine milk
}

\author{
S. Maye, ${ }^{*} \dagger$ C. Stanton, ${ }^{*}$ G. F. Fitzgerald, $†$ and P. M. Kelly* \\ *Teagasc Food Research Centre, Moorepark, Fermoy, County Cork, Ireland \\ †Microbiology Department, University College Cork, Cork, Ireland
}

\begin{abstract}
Complement activity has only recently been characterized in raw bovine milk. However, the activity of this component of the innate immune system was found to diminish as milk was subjected to heat or partitioning during cream separation. Detection of complement in milk relies on a bactericidal assay. This assay exploits the specific growth susceptibility of Escherichia coli O111 to the presence of complement. Practical application of the assay was demonstrated when a reduction in complement activity was recorded in the case of pasteurized and reduced-fat milks. This presented an opportunity to improve the functionality of the bactericidal assay by incorporating bioluminescence capability into the target organism. Following some adaptation, the strain was transformed by correctly integrating the p16Slux plasmid. Growth properties of the transformed strain of $E$. coli $\mathrm{O} 111$ were unaffected by the modification. The efficacy of the strain adaptation was correlated using the LINEST function analysis $[\mathrm{r}=$ 0.966 ; standard error of prediction $(\mathrm{SEy})=0.957]$ bioluminescence with that of bactericidal assay total plate counts within the range of 7.5 to $9.2 \log \mathrm{cfu} / \mathrm{mL}$ using a combination of raw and processed milk samples. Importantly, the transformed E. coli O111 p16Slux strain could be identified in milk and broth samples using bioluminescence measurement, thus enabling the bactericidal assay-viability test to be monitored in real time throughout incubation.
\end{abstract}

Key words: complement, bactericidal activity, bovine, milk, milk fat globule membrane

\section{INTRODUCTION}

Bovine milk is substantially adapted during the production of humanized infant milk formula to align its composition with that of human breast milk. However,

Received August 11, 2015.

Accepted September 23, 2015.

${ }^{1}$ Corresponding author: phil.kelly@teagasc.ie although much progress has been made in addressing nutritional needs of the neonate, little attention has been given to the activity of milk's defense systems. Complement, a part of the innate immune system, is made up of approximately 29 distinct plasma proteins that interact to opsonize pathogens and induce a series of inflammatory responses to help fight infection by killing invading microorganisms (Rainard, 2003). Complement is known to be present and anti-pathogenic in human breast milk (Ogundele, 2001), and its presence and activity in bovine milk have also been identified (Rainard et al., 1984; Barrio et al., 2003; Rainard, 2003; Maye et al., 2015). Recent efforts to characterize complement activity in milk has relied on the use of a bactericidal assay, which exploits the sensitivity of a specific strain of Escherichia coli O111 [E. coli NCTC 8007, serotype O111 K58 (B4) H2] to this innate immune protein system (Monteiro-Neto et al., 1997; Ogundele, 1998). Thus, the growth of added E. coli $\mathrm{O} 111$ is delayed as a result of the active complement in milk; the extent of growth inhibition of the pathogen may be used as an indirect measure of complement activity (Reiter and Brock, 1975). In practice, the activation of complement proteins via a cascading pathway is the mechanism that destroys bacteria in multiple ways (Frank and Fries, 1991). Examples of where this bactericidal assay technique has been applied include the measurement and identification of complement activity in mastitic and human milks (Rainard et al., 1984; Barrio et al., 2003).

We were recently successful in applying the bactericidal assay to establish complement activities in freshly drawn bovine milks. Furthermore, it was also discovered that the complement response was considerably reduced during exposure of bovine milks to simulated milk processes such as heating and preparation of low-fat milks. Inactivation of indigenous enzymes in milk such alkaline phosphatase is a commonly used bio-marker to prove the efficacy of milk pasteurization. This study was less concerned with the use of complement as a bio-marker for calibrating the effectiveness of thermal processes, but more interested in the preservation, where possible, of the innate immune properties of milk. 
As bovine milk is subjected to considerable processing during manufacture of infant milk formula, it was felt that an improved bactericidal assay would be more useful for real-time monitoring during operations that give rise to reduced complement activity. Lux tagging of the target microorganism was deemed to be an appropriate strategy that would allow bioluminescent signals to reflect growth and bioluminescence imaging to visualize the magnitude of bacterial inhibition speedily during the viability test. Thus, the initial step was to develop a method to introduce the plasmid, p16Slux (Riedel et al., 2007a; Morrissey et al., 2011) containing the lux operon derived from Photorhabdus luminescens into the $E$. coli O111 strain. One challenge with this approach was a lack of available data on successful genetic modifications to E. coli O111. In addition, previous work aimed at rapid detection of this strain identified the existence of several phenotypes of the O111 organism (Schmidt and Karch, 1996). However, a background of successful adaptations involving the p16Slux plasmid labeling of different strains and microorganisms without affecting mutation exists (e.g., lux-tagging of gram-negative strains such as E. coli, Salmonella enterica serovar Typhimurium, Yersinia enterocolitica, Brucella melitensis, Pseudomonas aeruginosa, and Citrobacter rodentium; Riedel et al., 2007a).

Thus, the study's 2-fold objective was, first, to undergo strain transformation to ensure consistent expression of the p16Slux in E. coli O111. Second, it was necessary to compare and contrast the growth behavior of the transformed E. coli O111 strain alongside that of the original unmodified culture according to the protocol of the regular bactericidal assay.

\section{MATERIALS AND METHODS}

\section{Bacterial Strains, Media, and Chemicals}

Escherichia coli O111 [E. coli NCTC 8007, serotype O111 K58 (B4)], a pathogenic complement-sensitive strain, was purchased from Health Protection Agency Culture Collections (Health Protection Agency Culture Collections, Porton Down, UK). The strain was routinely grown in Luria-Bertani $(\mathbf{L B})$ medium at $37^{\circ} \mathrm{C}$ with shaking. When required, the antibiotic erythromycin (Sigma Chemical Company, St. Louis, MO) was added at a concentration of $500 \mu \mathrm{g} / \mathrm{mL}$.

\section{Preparation of Competent Cells and Electroporation}

Originally, a method described by Dagert and Ehrlich (1979) was undertaken that required the withdrawal of $2 \mathrm{~mL}$ from a flask containing $200 \mathrm{~mL}$ of sterile LB broth and its replacement with $2 \mathrm{~mL}$ of an overnight culture grown in LB medium. The inoculated medium was grown at $37^{\circ} \mathrm{C}$ for approximately $2 \mathrm{~h}$ or until the optical density at $600 \mathrm{~nm}\left(\mathbf{O D}_{600}\right)$ was within the range of 0.6 to 1.0. At this point, the $200 \mathrm{~mL}$ was equally distributed into 4 sorvall tubes and the cells were harvested by centrifugation at room temperature for 15 min at $15,000 \times g$. A cell pellet was collected and washed twice with distilled water. The cell pellet was then washed using glycerol and finally resuspended in glycerol, which contained on average $10^{9}$ to $10^{10}$ viable bacteria.

Unfortunately, this method was unsuccessful and no viable electrocompetent cells were established. Fortunately, a second method applied called for $2 \mathrm{~mL}$ of the overnight cultures to be added to $200 \mathrm{~mL}$ of LB broth before growing to an $\mathrm{OD}_{600}$ of 0.2 to 0.4 in approximately $2.5 \mathrm{~h}$. The cells were harvested by centrifugation at $21^{\circ} \mathrm{C}$ for $5 \mathrm{~min}$ at $5,000 \times g$ and washed twice using $\mathrm{CaCl}_{2}$. The cells were incubated on ice for $2 \mathrm{~h}$ between washes. The cell pellet was finally collected and re-suspended in glycerol and stored at $-80^{\circ} \mathrm{C}$ until required. This method proved to be effective against $E$. coli $\mathrm{O} 111$ and produced electrocompetent cells.

The plasmid p16Slux, kindly donated by Colin Hill's research group in University College Cork, Ireland, was prepared using the Qiagen mini-prep kit as previously described, and integrated into the E. coli O111 bacterial chromosome by homologous recombination (Riedel et al., 2007b). For electroporation, $7 \mu \mathrm{L}$ of the p16Slux was purified using the Qiagen plasmid mini-prep kit and was mixed with $50 \mu \mathrm{L}$ of the electrocompetent $E$. coli O111. This mixture was transferred to a 5 -mm gap width electroporation cuvette and placed in a BTX Electroporation System (Harvard Apparatus, Holliston, MA).

\section{Sample Preparation}

Fresh whole milk was collected from the Moorepark dairy production center farm on the day of testing. An Armfield disc bowl centrifuge (Armfield, Ringwood, UK) was used in the laboratory to generate cream samples (approximately 40\% fat) and skim milk (approximately $1 \%$ fat) from the fresh raw milk. Commercially pasteurized bovine milk was purchased from local supermarkets on the day of testing.

All samples were analyzed for total bacteria count using the reference IDF method (IDF, 2004; IDF, 2013). The SCC of the raw, skimmed, and retailed milks were was determined using a Bentley Somacount 300 (Bentley Instrument Inc., Chaska, MN). Milks with SCC $<200,000$ cells per $\mathrm{mL}$ were selected for bactericidal 
assay to avoid false-positive results being contributed by the presence of other immune factors triggered in the wake of mammary infection.

\section{Control Preparation}

Freshly collected raw milk was heat treated at $56^{\circ} \mathrm{C}$ for $30 \mathrm{~min}$ to ensure complete inactivation of the complement protein (Korhonen et al., 2000). All samples were screened using the IDF methods (IDF, 2004, 2013), and also the milks were streaked on nutrient and LB agar.

\section{Bactericidal Assay-Viability Test}

Escherichia coli $\mathrm{O} 111$ and transformed E. coli $\mathrm{O} 111$ were prepared for overnight growth at $37^{\circ} \mathrm{C}$ on $\mathrm{LB}$ agar as described (Sambrook et al., 2001). Isolated colonies were picked from replicate plates and inoculated into 3 tubes of nutrient broth (Merck KGaA, Darmstadt, Germany) and grown overnight at $37^{\circ} \mathrm{C}$ at $200 \mathrm{rpm}$. After approximately 18 to $24 \mathrm{~h}$, the overnight cultures were centrifuged at $21^{\circ} \mathrm{C}, 14,000 \times g$, followed by resuspension of the resulting pellet in PBS solution; this step was replicated twice. Following this, the pellet was resuspended in LB broth and adjusted to $3 \times 10^{8} \mathrm{cfu}$ per $\mathrm{mL}$ using the McFarland method. Using 96-well plates, $3 \times 20 \mu \mathrm{L}$ of both strains was added to each round-bottomed well (Sarstedt Ltd., Wexford, Ireland), and $80 \mu \mathrm{L}$ of the sample to be tested was then added. The plate was placed in a shaking incubator (model Mini 4450 SHKA4450-1CE, Fisher Scientific, Dublin, Ireland) at $200 \mathrm{rpm}$ for $2 \mathrm{~h}$ at $37^{\circ} \mathrm{C}$. A $20-\mu \mathrm{L}$ sample was taken from each well after incubation; total viable counts were enumerated on LB agar.

\section{Monitoring of Growth in LB Broth by Performing Viable Plate Counts and Measuring Bioluminescence}

Overnight cultures of both the wild type (WT) and transformed E. coli strain were grown in LB broth. Erythromycin was included in the LB broth to support the transformed strain from reverting to its original form. These were centrifuged at room temperature for 15 min at a speed of $5,000 \times g$, followed by washing with PBS and resuspension in LB broth. Twenty microliters of inoculum was then added to fresh LB broth and grown in a shaking incubator at a speed of $200 \mathrm{rpm}$ and temperature of $37^{\circ} \mathrm{C}$. Samples were collected at 1-h intervals, and viable plate counts were carried out to by plating dilutions onto LB agar. Two hundred microliters of the freshly inoculated LB broth was added to a 96-well white plate (Nunc, Thermo Fisher Scientific, Roskilde, Denmark), and optical density was measured hourly using a Synergy HT plate reader (Bio-Tek In- struments Inc., Winooski, VT). Simultaneously, bioluminescence was also measured in photons per second per square centimeter with an IVIS Xenogen Imaging 100 system (Xenogen, Alameda, CA) with a binning of 16 and an exposure time of $1 \mathrm{~min}$.

\section{Evaluation of Minimum Inhibitory Concentration of the WT and Transformed E. coli 0111 in Erythromycin}

Both strains of E. coli O111 were tested according to the M.I.C.E strips (Oxoid Ltd., Basingstoke, UK) method, which gives an accurate minimum inhibitory concentration over the range of 256 to $0.015 \mu \mathrm{g} / \mathrm{mL}$. This was to confirm that tolerance to erythromycin of p16Slux plasmid was conferred on E. coli O111 following transformation (Riedel et al., 2007a).

\section{Molecular Biology Experiments}

The PCR reactions were performed on the WT $E$. coli O111 and transformed E. coli O111 using Biomix red (Mybio, Kilkenny, Ireland); primers were purchased from Eurofins (MWG, Ebersberg, Germany), $16 \mathrm{~S}$ forward (5'-ACACTGGAACTGAGACACGGTCCAGACTCC-3') and $16 \mathrm{~S}$ reverse (5'-TTGTAAAACGACGGCCAGTGAGCGCGCG-3'), to verify that the p16Slux plasmid had correctly integrated at the preferred location. The PCR reactions were carried out using a T3000 Thermocycler (Biometra, Gottingen, Germany) as previously described (Morrissey et al., 2011) with the addition of a preliminary "hotstart" step. Gel electrophoresis was performed using the Power pack 200 (Bio-Rad, Hercules, CA); $4 \mu \mathrm{L}$ of the PCR products were routinely run on $1 \%$ agarose gels (Invitrogen, Carlsbad, CA) at $90 \mathrm{~V}$ and $2 \mathrm{~A}$ for $60 \mathrm{~min}$.

\section{RESULTS AND DISCUSSION}

\section{Transformation E. coli 0111 Strain}

The induced mutation proved to be challenging due to the relatively unknown response of $E$. coli O111 to genetic transformation and shortage of data in existence for the relevant strain. Moreover, a relevant study to rapidly identify E. coli $\mathrm{O} 111$ in food recognized much variance in phenotype within the O111 group, which suggested possible difficulties were likely during attempts to modify the strain (Schmidt and Karch, 1996). For this reason, the initial method to prepare an electrocompetent strain was unsuccessful, whereas the second method, which featured additional adaptations such as the use of calcium chloride and altered temperature regimens, was ultimately effective. 


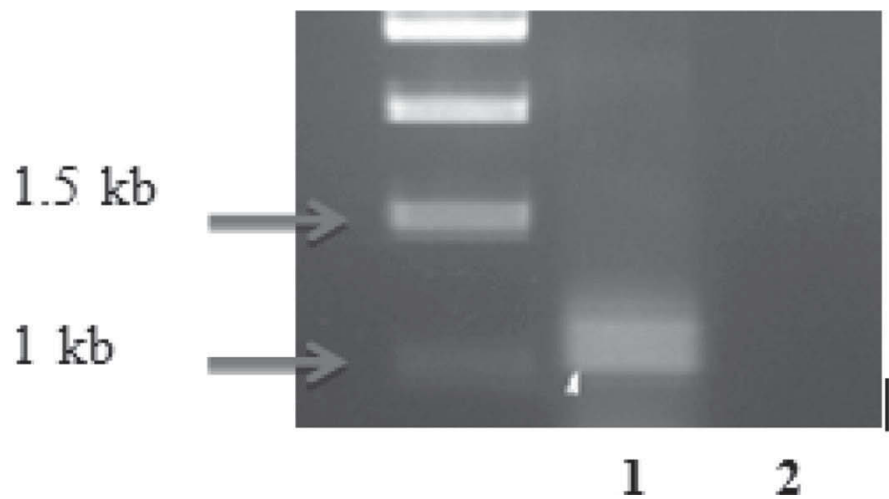

Figure 1. Electrophoresis gel shows the approximately 1,163-bp band that confirms the presence of the p16Slux plasmid, which integrates in the $16 \mathrm{~S}$ rRNA gene of gram-negative bacteria. Lane 1 is the p16 transformed strain, lane 2 is the wild type strain; as expected, a band is present in lane 1, indicating the successful integration of the plasmid in the correct position.

Finally, the p16Slux plasmid became well established within E. coli O111 following electroporation (Riedel et al., 2007a). The exact location of plasmid integration was confirmed by means of PCR using primers specifically designed to address the target integration site. Gel electrophoresis carried out on PCR products (e.g., the identification of a 1,163-bp band produced) confirmed the correct positioning of the plasmid (Figure 1). Furthermore, PCR and gel electrophoresis performed on

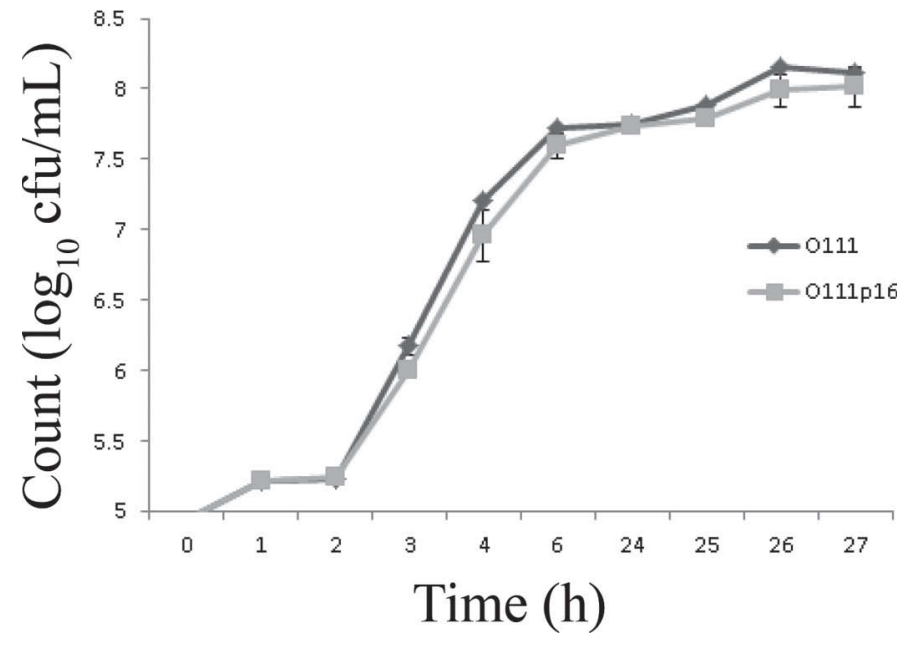

Figure 2. Total viable count of Escherichia coli O111 in addition to the genetically modified p16Slux E. coli $\mathrm{O} 111\left(\log _{10} \mathrm{cfu} / \mathrm{mL}\right)$, grown overnight at $37^{\circ} \mathrm{C}$ for $27 \mathrm{~h}$ in Luria-Bertani broth. Error bars indicate standard deviation of triplicate assessments.

the unmodified E. coli O111 strain revealed that no PCR product was amplified from this strain.

\section{Comparison of Original and Transformed Strains}

Observation of Growth Properties of Both Strains. The wild and genetically modified strains of E. coli O111 grown on LB agar were similar in terms of

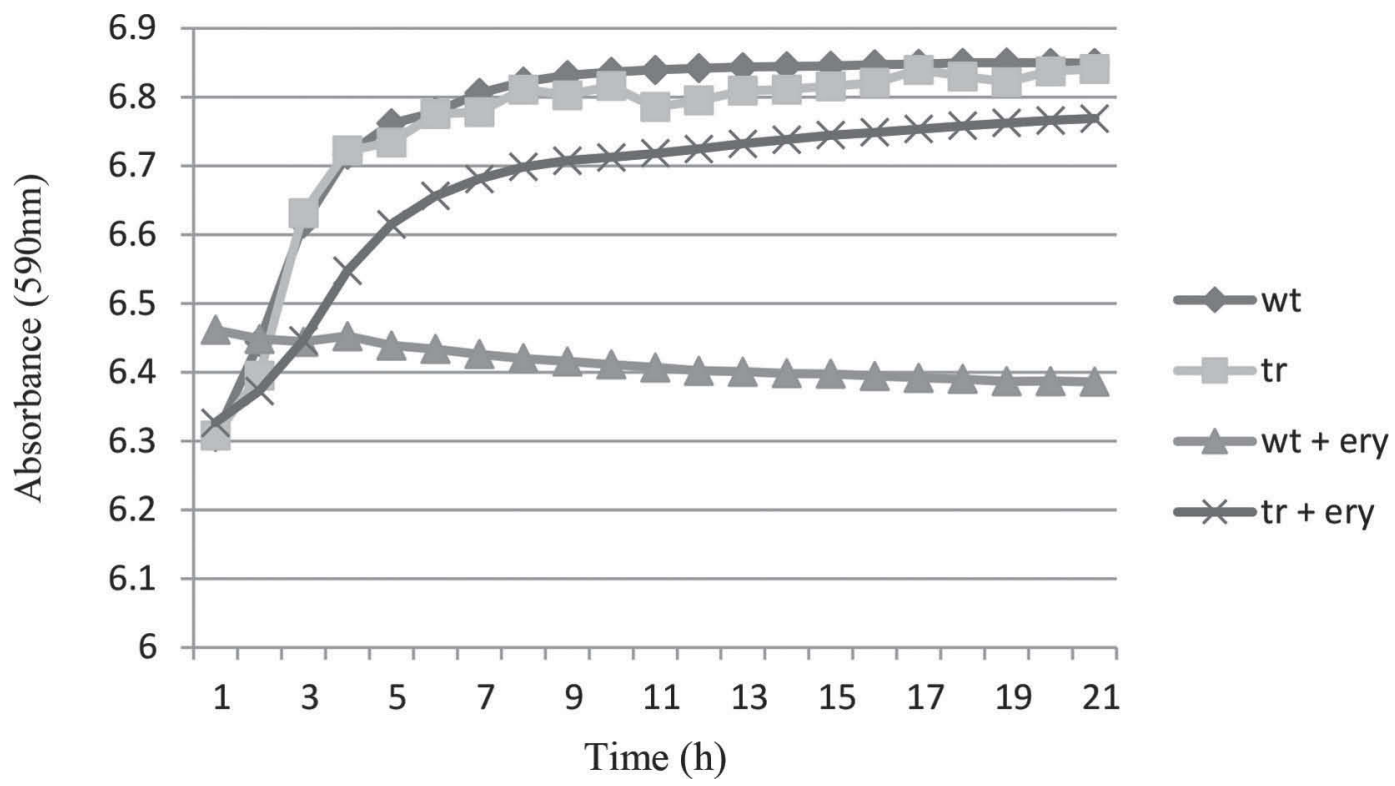

Figure 3. Absorbance readings (590 nm) of Escherichia coli O111 in Luria-Bertani (LB) broth (wt), genetically modified E. coli O111 in LB broth (tr), wild type $E$. coli $\mathrm{O} 111$ in LB broth with $500 \mu \mathrm{g} / \mathrm{mL}$ of erythromycin (wt + ery), genetically modified $E$. coli O111 in LB broth with $500 \mu \mathrm{g} / \mathrm{mL}$ of erythromycin (tr + ery) during incubation at $37^{\circ} \mathrm{C}$ for $21 \mathrm{~h}$. 
size, shape (round), and color (cream). Furthermore, no significant difference $(P>0.05)$ was identified through enumeration of total viable counts during overnight growth of the isolated colonies of both strains in LB broth at $37^{\circ} \mathrm{C}$ (Figure 2), as well as throughout hourly measurement of absorbance readings $(590 \mathrm{~nm})$ as seen in Figure 3.

Furthermore, the luminescence remained relatively stable throughout the entire growth curve (results not shown), as was seen in previous studies (Riedel et al., 2007a); this was confirmed by the correlation between the reduction in luminescence region of interest (ROI) and respective colony-forming unit counts. Overall, it can be concluded that the growth properties of $E$. coli O111 strain remained intact after genetic modification involving plasmid insertion.

Confirmation of Effects p16 Slux Plasmid. Confirmation of acquired antibiotic resistance in the newly transformed strain to erythromycin was demonstrated during $21 \mathrm{~h}$ incubation at $37^{\circ} \mathrm{C}$ in LB broth in the presence of erythromycin (Figure 3), whereas the WT E. coli $\mathrm{O} 111$ was unable to grow under these conditions. In addition, the transformed strain produced strong bioluminescent readings in the images (Figure 4a and 4b) captured from the Xenogen IVIS, whereas the WT strain did not release any bioluminescence.

Confirmation of tolerance to erythromycin of the transformed E. coli O111 strain is evident according to the lack of inhibition in the immediate zones of the M.I.C.E strips (Figure 5), thus concurring with the functionality cited for the plasmid insert by Riedel et al. (2007a). By contrast, a considerable area of clearance may be seen in the case of the WT strain.

Application of Transformed E. coli 0111 p16Slux Plasmid. Bioluminescent imaging was monitored in real time during the performance of the bactericidal assay involving the transformed E. coli $\mathrm{O} 111$ strain. The efficacy of strain adaptation was illustrated by the bioluminescent images captured, initially and after $2 \mathrm{~h}$ (Figure 6) shaking incubation $\left(37^{\circ} \mathrm{C}\right.$ at 200 $\mathrm{rpm})$ of p16Slux E. coli $\mathrm{O} 111$ in heat-treated $\left(56^{\circ} \mathrm{C}, 30\right.$ min) milk, freshly collected raw milk, skim milk, and commercially retailed full-fat milk.

The luminescent data overlaid on the photographic image of the clear 12-well plate (Figure 6) uses a pseudocolor scheme that aids in the observation of light emission. In the brighter area of the image, more photons are detected and the photon intensity number is greater than in the less bright areas.

This is best described by tracking color change from the time of initial inoculation to termination after 2 h incubation of p16Slux E. coli O111 in a variety of treated milk substrates. Exponential growth of the culture in retailed pasteurized milk and heated bovine a)

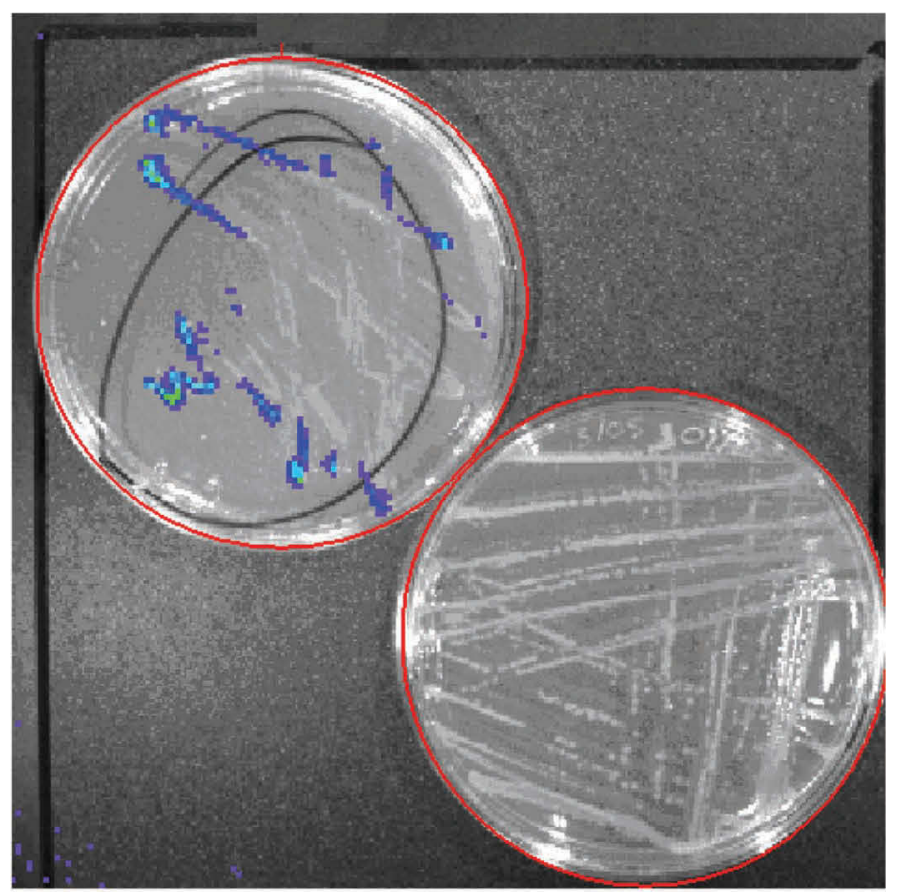

b)

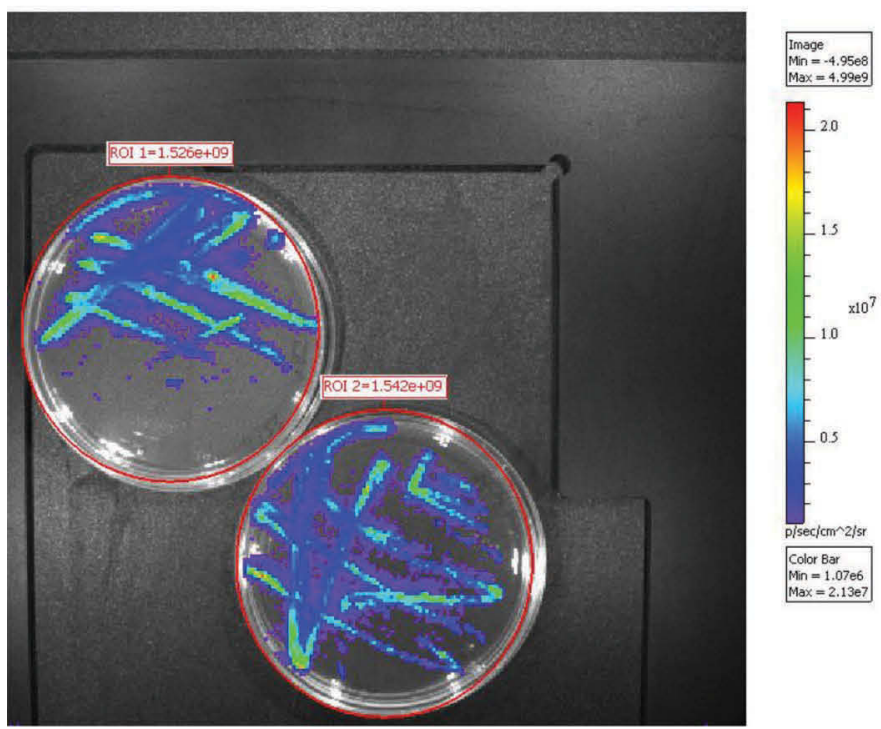

Figure 4. (a) Bioluminescence image of transformed Escherichia coli O111 alongside the original unmodified wild type strain of $E$. coli O111. The image was captured on a Xenogen IVIS 100 imager (Xenogen, Alameda, CA), and the culture was grown overnight on Luria-Bertani (LB) agar at $37^{\circ} \mathrm{C}$. (b) Bioluminescence image of transformed Escherichia coli O111; the image was captured on a Xenogen IVIS 100 imager, and culture was grown overnight on LB agar at $37^{\circ} \mathrm{C}$. Color version available online. 
a)

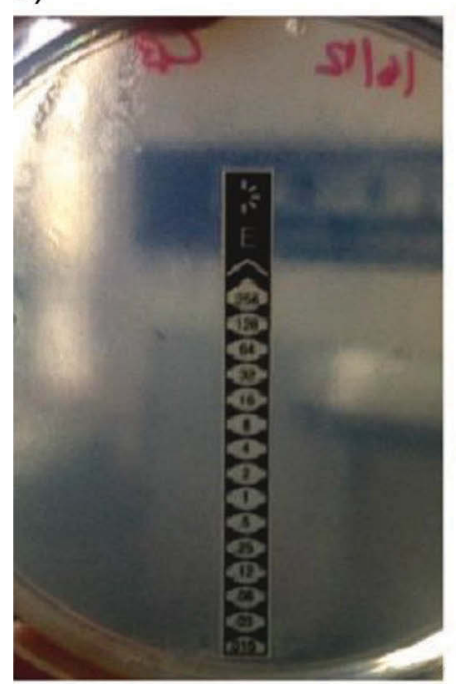

b)

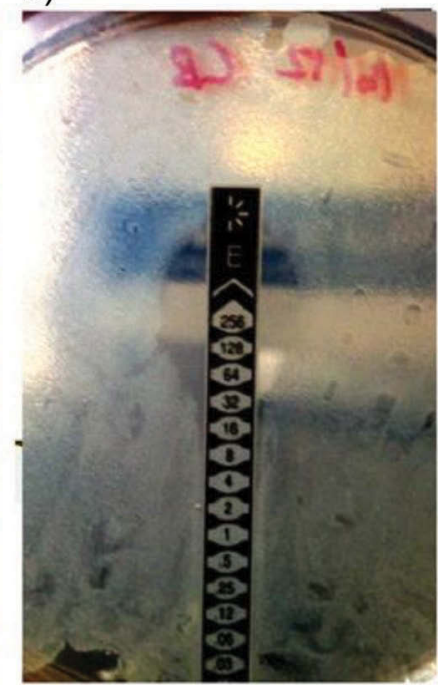

Figure 5. (a) Lack of inhibition in the immediate zones of the M.I.C.E strips (Oxoid Ltd., Basingstoke, UK) provides confirmation of tolerance to erythromycin of the transformed Escherichia coli O111 strain. (b) A considerable area of clearance may be seen in the case of the wild type strain. Color version available online.

milk was represented by bright red and yellow light emission. However, the lighter blue colored zones were a consequence of lower light emission when the growth of transformed E. coli O111 was restrained in skim milk, and most notably, in the raw bovine milk (due to complement activity).

The corresponding results generated by the bactericidal assay using the genetically modified E. coli $\mathrm{O} 111$ p16Slux strain for the control heat-treated milk $\left(56^{\circ} \mathrm{C}\right.$, 30 min), raw bovine milk, commercial retailed milk, and laboratory-prepared skim milk were 9.18, 8.60, 7.64, and $9.02 \log _{10} \mathrm{cfu} / \mathrm{mL}$, respectively (Figure 7 ). These data coincided with the ROI photon measurements undertaken concurrently where the differences in bioluminescence intensity reflected changes in the aforementioned bacterial growth. The total viable counts of $E$. coli $\mathrm{O} 111$ in raw bovine milk lower $(P$ $<0.05$ ) compared with skim, retail pasteurized, and heat-treated control bovine milks reflected its stronger bacteriostatic effect due to complement (Reiter and Brock, 1975; Reiter et al., 1975).

Hence, incorporation of bioluminescent imaging via genetic modification to enhance the functionality of the probe microorganism is an effective enhancement of the assay for monitoring complement activity in various unprocessed and processed milks. According to the
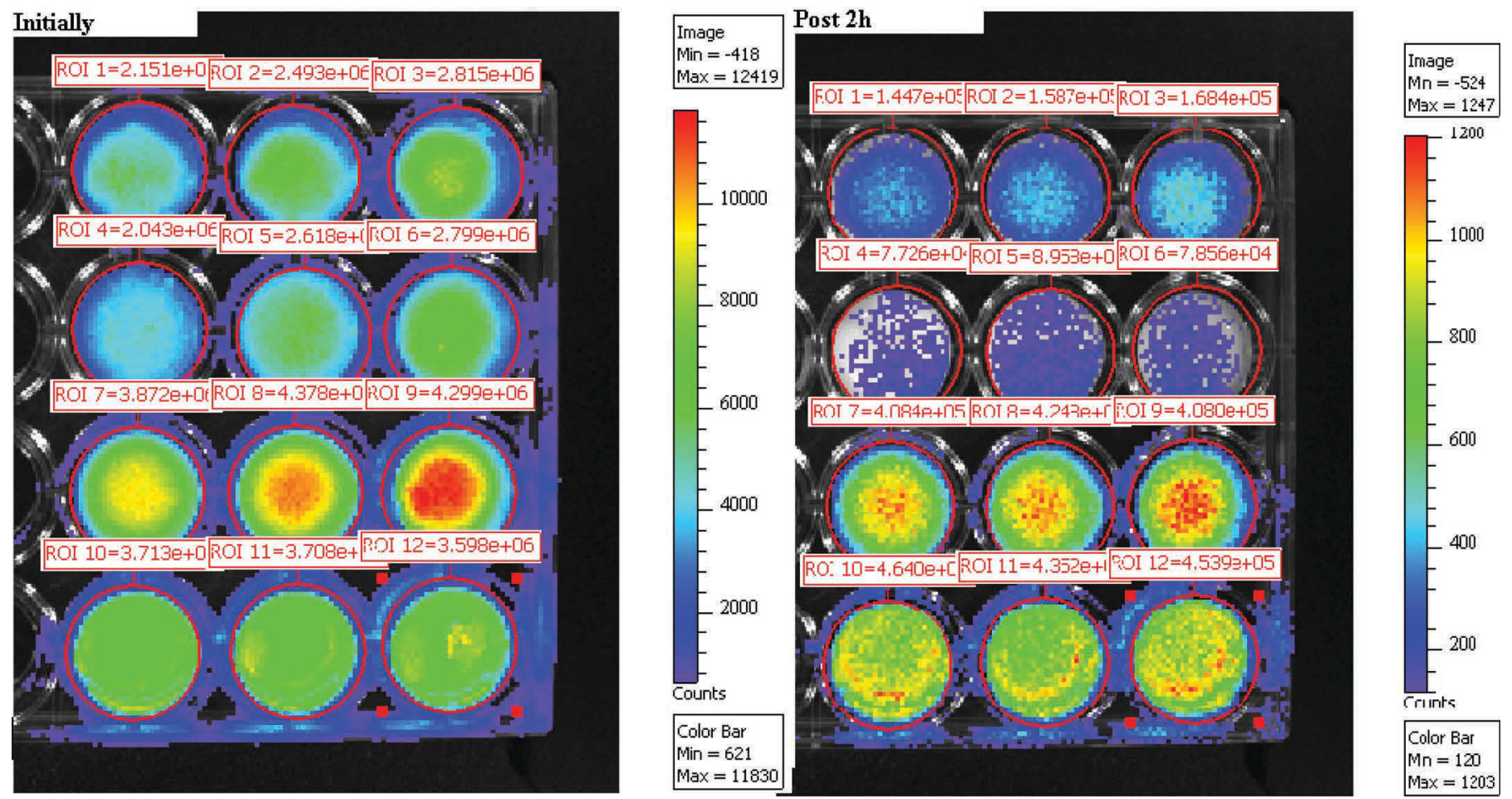

Figure 6. Growth of transformed Escherichia coli O111 at initial inoculation and following $2 \mathrm{~h}$ incubation in (i) skim milk, (ii) raw bovine milk, (iii) commercial pasteurized milk, and (iv) heated bovine milk (control) during the bactericidal assay for $2 \mathrm{~h}$ at $37^{\circ} \mathrm{C}$. Bacteria were counted in the red circled regions of interest (ROI). 


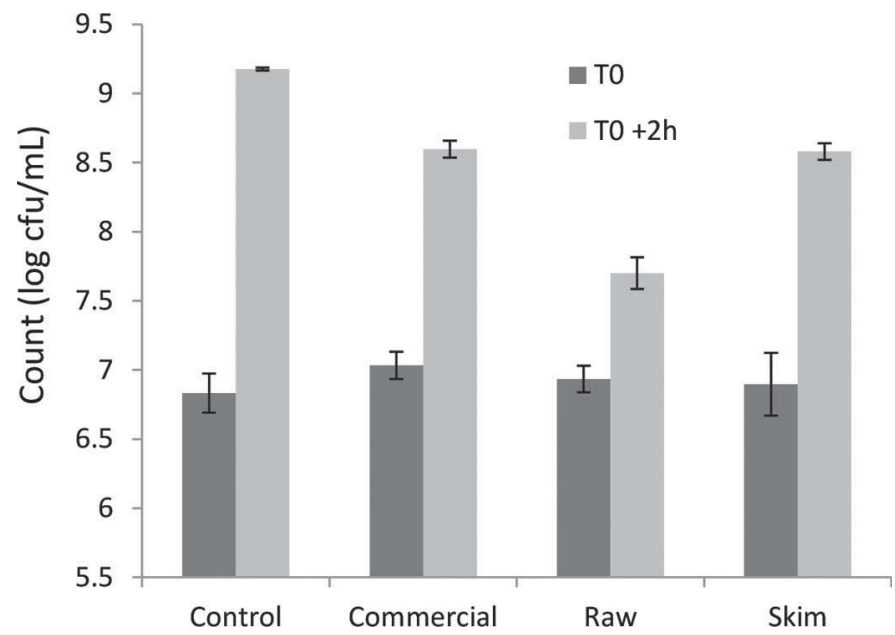

Figure 7. Growth of the transformed Escherichia coli O111 p16Slux $\left(\log _{10} \mathrm{cfu} / \mathrm{mL}\right)$ during bacterial sequestration assay at $0 \mathrm{~h}$ and following $2 \mathrm{~h}$ incubation with (i) heated bovine milk (control), (ii) commercial pasteurized milk, (iii) raw bovine milk, and (iv) laboratoryprepared skim bovine milk. Error bars indicate standard deviation of triplicate assessments.

independent-samples $t$-test, a significant difference $(P$ $<0.05)$ was present between all samples tested and the raw bovine milk, whereas statistically no significant difference $(P>0.05)$ was present between the laboratoryprepared skim milk and retail pasteurized samples.

Interrelationship Between Bacterial Counts and Bioluminescence of $\mathbf{E}$. coli $\mathrm{O} 111$. The interre- lationship between the traditional total bacteria counts and the adapted bioluminescent measurements was analyzed in Figure 8. It can be seen that the adapted bioluminescent-based sequestration method is strongly correlated with the old one according to the equation $y$ $=0.9748 \mathrm{x}+0.2133$ with a correlation coefficient $(\mathrm{r})$ of 0.966 and a coefficient of determination $\left(\mathrm{R}^{2}\right)$ of 0.933 . The standard error of prediction value is 0.957 .

These studies confirm that the objective of inserting a p16Slux plasmid into E. coli O111 to generate a bioluminescent response during subsequent growth was successfully accomplished. This transformed strain, which was originally used as an analytical probe in the biosequestration assay to detect the presence of complement activity in human milk (Ogundele, 1998), and more recently in bovine milk (Maye et al., 2015) may now be used to measure antimicrobial response in real time throughout the bactericidal assay. This adds greater certainty to the test given the diversity of other bacterial strains present in nonpasteurized milk, in particular, which may lead to the risk of false positive identifications. Furthermore, erythromycin resistance conferred on the transformed E. coli O111 also allows the strain to be selectively screened for by means of susceptibility tests with antibiotic agars.

Finally, application of the now upgraded bactericidal assay confirmed the earlier findings of Maye et al. (2015) that pasteurization (retail pasteurized milk) and cream removal (laboratory-separated skim milk)

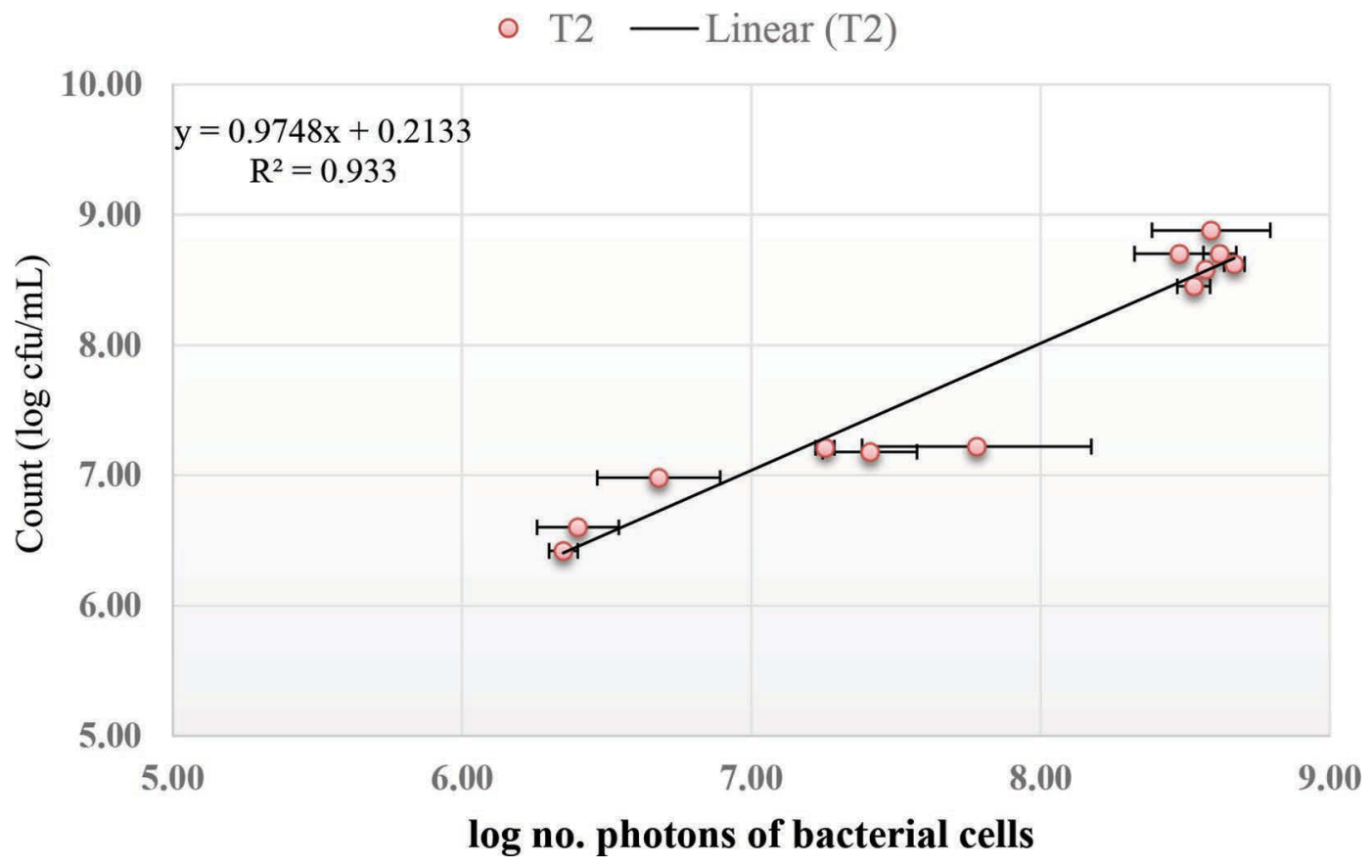

Figure 8. Interrelationship between the bacterial counts of Escherichia coli O111 measured by luminescence and total plate counts. Color version available online. Error bars indicate standard deviation of triplicate assessments. 
contributed to substantial loss of complement activity, but fortuitously, some residual complement activity is detectable in both the laboratory-prepared skim milk and pasteurized milk.

\section{ACKNOWLEDGMENTS}

Susan Maye is in receipt of a Teagasc Walsh Fellowship. Financial support by the Department of Agriculture, Food and Marine (Dublin, Ireland) FIRM-funded research programme is gratefully acknowledged.

\section{REFERENCES}

Barrio, M. B., P. Rainard, and B. Poutrel. 2003. Milk complement and the opsonophagocytosis and killing of Staphylococcus aureus mastitis isolates by bovine neutrophils. Microb. Pathog. 34:1-9.

Dagert, M., and S. Ehrlich. 1979. Prolonged incubation in calcium chloride improves the competence of Escherichia coli cells. Gene $6: 23-28$.

Frank, M. M., and L. F. Fries. 1991. The role of complement in inflammation and phagocytosis. Immunol. Today 12:322-326.

IDF. 2004. Milk-Quantitative determination of bacteriological quality-Guidance for establishing and verifying a conversion relationship between routine method results and anchor method results. International Organization for Standardization, Geneva Switzerland, and International Dairy Federation, Brussels, Belgium. First edition (ISO 21187/IDF 196).

IDF. 2013. Milk-Bacterial count-Protocol for the evaluation of alternative methods. International Organization for Standardization, Geneva Switzerland, and International Dairy Federation, Brussels, Belgium. First ed. (ISO 16917/IDF 161).

Korhonen, H., P. Marnila, and H. Gill. 2000. Milk immunoglobulins and complement factors. Br. J. Nutr. 84:S75-S80.

Maye, S., C. Stanton, G. F. Fitzgerald, and P. M. Kelly. 2015. Detection and characterisation of Complement protein activity in bovine milk by bactericidal sequestration assay. J. Dairy Res. 82:328-333.

Monteiro-Neto, V., L. Carvalho Campos, A. J. Piantino Ferreira, T. A. Tardelli Gomes, and L. R. Trabulsi. 1997. Virulence proper- ties of Escherichia coli O111:H12 strains. FEMS Microbiol. Lett. 146:123-128.

Morrissey, R., M. Begley, S. Oshima, M. Rea, R. P. Ross, and C. Hill. 2011. Real-time monitoring of luciferase-tagged Cronobacter sakazakii in reconstituted infant milk formula. J. Food Prot. 74:573579.

Ogundele, M. O. 1998. New Insights into the Role of Milk Fat Globule Membrane in the Sequestration of Particulate Antigens: Interactions with the Complement System. In Proc. 5th Internet World Congress for Biomedical Sciences, McMaster University, Hamilton, Ontario, Canada.

Ogundele, M. O. 2001. Role and significance of the complement system in mucosal immunity: Particular reference to the human breast milk complement. Immunol. Cell Biol. 79:1-10.

Rainard, P. 2003. The complement in milk and defense of the bovine mammary gland against infections. Vet. Res. 34:647-670.

Rainard, P., B. Poutrel, and J. P. Caffin. 1984. Assessment of hemolytic and bactericidal complement activities in normal and mastitic bovine milk. J. Dairy Sci. 67:614-619.

Reiter, B., and J. Brock. 1975. Inhibition of Escherichia coli by bovine colostrum and post-colostral milk. I. Complement-mediated bactericidal activity of antibodies to a serum susceptible strain of $E$. coli of the serotype O111. Immunology 28:71-82.

Reiter, B., J. Brock, and E. D. Steel. 1975. Inhibition of Escherichia coli by bovine colostrum and post-colostral milk. II. The bacteriostatic effect of lactoferrin on a serum susceptible and serum resistant strain of E. coli. Immunology 28:83-95.

Riedel, C. U., P. G. Casey, H. Mulcahy, F. O'Gara, C. G. Gahan, and C. Hill. 2007a. Construction of p16Slux, a novel vector for improved bioluminescent labeling of gram-negative bacteria. Appl. Environ. Microbiol. 73:7092-7095.

Riedel, C. U., I. R. Monk, P. G. Casey, D. Morrissey, G. C. O'Sullivan, M. Tangney, C. Hill, and C. G. Gahan. 2007b. Improved luciferase tagging system for Listeria monocytogenes allows real-time monitoring in vivo and in vitro. Appl. Environ. Microbiol. 73:30913094.

Sambrook, J., D. W. Russell, and D. W. Russell. 2001. Molecular Cloning: A Laboratory Manual (3-volume set). Vol. 999. Cold Spring Harbor Laboratory Press, Cold Spring Harbor, New York.

Schmidt, H., and H. Karch. 1996. Enterohemolytic phenotypes and genotypes of shiga toxin-producing Escherichia coli O111 strains from patients with diarrhea and hemolytic-uremic syndrome. J. Clin. Microbiol. 34:2364-2367. 